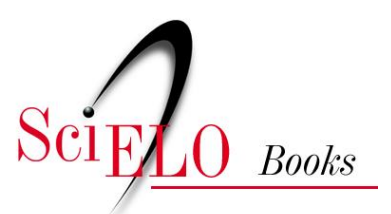

EDUFU

\title{
4 - O quadro aspectual do Português
}

\author{
Luiz Carlos Travaglia
}

\section{SciELO Books / SciELO Livros / SciELO Libros}

TRAVAGLIA, L.C. O quadro aspectual do Português. In: $O$ aspecto verbal no português: a categoria e sua expressão [online]. 5th ed. Uberlândia: EDUFU, 2016, pp. 73-102. ISBN: 978-65-5824-014-3. https://doi.org/10.7476/9786558240143.0006.

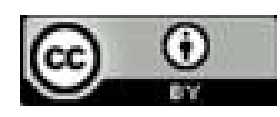

All the contents of this work, except where otherwise noted, is licensed under a Creative Commons Attribution 4.0 International license.

Todo o conteúdo deste trabalho, exceto quando houver ressalva, é publicado sob a licença Creative Commons Atribição $\underline{4.0}$.

Todo el contenido de esta obra, excepto donde se indique lo contrario, está bajo licencia de la licencia Creative Commons Reconocimento 4.0. 


\section{4 - O quadro aspectual do Português}

\section{1 - DA IMPROPRIEDADE DE UM QUADRO DE ASPECTOS COMPOSTOS}

\subsection{1 - PRELIMINARES}

Conceituado o aspecto e determinadas as noções aspectuais, é preciso estabelecer um quadro aspectual, uma taxionomia dos aspectos. Nesta tarefa temos, basicamente, três possibilidades: estabelecer um quadro de aspectos compostos, um quadro de aspectos simples ou um quadro misto com aspectos simples e compostos.

Chamamos de compostos aqueles aspectos que são caracterizados por mais de uma noção aspectual. É o caso, por exemplo, do Perfectivo e Imperfectivo ${ }^{1}$ na definição que deles deram Castilho (1967) e Comrie (1976). Aspectos simples serão aqueles caracterizados por uma única noção aspectual. No quadro estabelecido por Câmara Jr. (cf. item 1.3.8) encontramos alguns exemplos de aspectos simples tais como o Inceptivo, o Inconcluso, o Pontual, entre outros.

$\mathrm{Na}$ argumentação a respeito da impropriedade dos aspectos compostos vamos nos valer, principalmente, do quadro proposto por Castilho (cf. item 1.3.9) não só por ser o único que fez um estudo mais sério do aspecto em Língua Portuguesa, mas também por ser o único que estabeleceu um quadro que busca dar conta de todos os casos possíveis em uma análise aspectual do Português.

\subsection{2 - Os ASPECTOS COMPOSTOS}

Procuraremos demonstrar aqui não só que um quadro de aspectos simples permite uma análise aspectual melhor, por ser mais simples e completa a análise

\footnotetext{
${ }^{1}$ Doravante, quando houver coincidência de terminologia, ao nos referirmos a um aspecto tal como definido por outros autores, ou a um aspecto que propomos para efeito de raciocínio, usaremos letra maiúscula; ao nos referirmos a um aspecto tomado como o definimos em nosso trabalho, usaremos letra minúscula.
} 
com um menor número de elementos; mas também uma série de impropriedades de análise que já deverão ser consideradas quando da proposição do quadro aspectual e sua aplicação na análise.

Para Castilho (1967), o perfectivo se caracteriza pela noção de completamento que ele entende como sinônima de acabamento uma vez que diz: "As nuanças decorrentes da ação totalmente decursa permitem subdividir o perfectivo em três tipos" (CASTILHO, 1967, p.50). Não há dúvidas quanto a isto já que Castilho o declara em diversas passagens: "Temos o aspecto perfectivo se se indica uma ação cumprida, contrária à noção de duração" (CASTILHO, 1967, p.14); “O perfectivo indica processo acabado" (CASTILHO, 1967, p.15). O perfectivo, para ele, também “designa a ação-ponto" (CASTILHO, 1967, p.54), já que o completamento "implica na indicação precisa do começo e do fim do processo, polos estes separados por um lapso de tempo extremamente curto e não significativo." (CASTILHO, 1967, p.50). Portanto o Perfectivo seria um aspecto composto caracterizado pelas noções de completamento (= acabamento) e pontualidade.

O imperfectivo é, pelo mesmo autor, caracterizado como sendo marcado pelo valor fundamental de duração (CASTILHO, 1967, p.49), indicando uma ação que dura (CASTILHO, 1967, p.41) uma ação-linha (CASTILHO, 1967, p.54). A duração apresentaria sempre um dentre três matizes (cf. item 1.3.9) que caracterizariam três subtipos: os aspectos Imperfectivo Inceptivo (noções de duração + início) Imperfectivo Cursivo (noções de duração + meio) e Imperfectivo Terminativo (noções de duração + fim). Portanto o Imperfectivo seria um aspecto composto em qualquer dos três subtipos que aparecesse.

Deve-se notar que ao caracterizar o Perfectivo e o Imperfectivo, Castilho não diz que este se caracteriza pelo não acabamento. Sua colocação faz pensar que ele opõe completamento no Perfectivo a duração no Imperfectivo, ou seja, podemos dizer que explicitamente Castilho não afirma que o Imperfectivo apresenta a ação como não acabada. Entretanto, pela oposição entre Perfectivo e Imperfectivo, isto parece ficar implícito.

Observem-se os exemplos abaixo, extraídos de Castilho (1967). Entre parênteses aparece o aspecto que ele disse estar presente na forma em negrito e a página de onde se extraiu o exemplo.

133. "Na sua voz irradiante começou logo a contar uma complicada história familiar, atravessada de traições, de direitos e de deveres". (Imperfectivo Inceptivo propriamente dito - p.63)

134. "Principiou a falar pausadamente, depois agitou-se, parecia um louco". (Imperfectivo Inceptivo propriamente dito - p.64) 
135. "Desatou a chorar convulsivamente". (Imperfectivo Inceptivo propriamente dito - p.65)

136. "Contemplou os seus livros com tanto afeto, como se em cada um estivesse uma página do seu coração". (Imperfectivo Cursivo propriamente dito - p.70)

137. "Firmina contou tudo. Como tinha sofrido coitadinho!" (Imperfectivo Cursivo propriamente dito - p.71)

138. "Há quase um século que correra sangue pelos seus campos". (Imperfectivo Cursivo propriamente dito - p.70)

139. "O patrão, que era um homem que gostava de fazer brincadeiras brutas, pensou, pensou, pensou e depois mandou recolher os pedintes". (Imperfectivo Cursivo propriamente dito - p.72)

140. "E foram que foram, andaram que andaram e chegaram na casa do pai de S. Francisco de Assis". (Imperfectivo Cursivo propriamente dito - p.72)

141. "À noite chamou a pequena e teve-a muito tempo apertada contra si". (Imperfectivo Cursivo propriamente dito - p.72)

142. "Dois dias e duas noites lhe escutaram os passos invariáveis de cá para lá de lá para cá, nas salas desertas". (Imperfectivo Cursivo propriamente dito - p.72-73)

143. "Estivera desmaiado tão pouco tempo, mas no elevador me parecia que eu tinha regressado de uma longa morte". (Imperfectivo Cursivo propriamente dito - p.75)

144. "[...] foi a Balsa que lhe inoculou através dos anos a seiva que faria dela a mulher sã e formosa..." (Imperfectivo Cursivo propriamente dito - p.76)

145. "Dioclécio foi transformando Antônio Bento, descobrindo para o criado do padre um mundo novo". (Imperfectivo Cursivo progressivo - p.77)

146. "Ao tédio e ao desespero substituiu-se gradualmente na alma de Jorge estranha inquietação.” (Imperfectivo Cursivo progressivo - p.78)

147. “A fita acabou e não falamos no incidente." (Imperfectivo Terminativo - p.79)

148. Terminada a festa, retiraram-se os convidados (Imperfectivo Terminativo - p.79)

149. "Só de ouvir dizer, porque, como acabo de contar, nunca os vira juntos." (Imperfectivo Terminativo - p.79-80) 
150. "[...] talvez porque lesse em meus olhos o que eu acabara de passar". (Imperfectivo Terminativo - p.80)

151. “Terminei de estudar a lição e saí à rua para espairecer”. (Imperfectivo Terminativo - p.80)

Nos exemplos (133) a (135) temos realmente uma duração "pressentida pelo falante" como diz Castilho. Acontece, porém, que essa duração não é das situações de "começar a contar", "principiar a falar" e "desatar a chorar" que são situações pontuais inceptivas (cf. item 3.2) e que nos exemplos aparecem como situações referenciais; a duração é das situações narradas (cf. item 3.3) "contar", "falar”e "chorar”. Vemos assim que as formas sublinhadas nestes exemplos não podem ter aspecto Imperfectivo porque aí não há duração, mas pontualidade e, além disso, as situações referenciais são apresentadas como acabadas. ${ }^{2}$ Portanto nos exemplos (133) a (135) teríamos, na verdade, aspecto Perfectivo. É preciso considerar, entretanto, que as situações são apresentadas em seu ponto de início e, portanto, há incepção. Para analisar o aspecto destas frases teríamos, pois, de acrescentar ao quadro de aspectos compostos um Perfectivo Inceptivo, que estaria presente em frases onde tivéssemos eventos cujo completamento (= acabamento) implica o início de uma situação durativa. Com estes três exemplos pudemos ver além de uma impropriedade de análise, a necessidade de proposição de mais um aspecto composto.

Nos exemplos (136) a (146), abstraindo da questão de ser progressivo ou não, já que a progressividade é uma noção não aspectual, teríamos segundo Castilho, o Imperfectivo Cursivo, portanto, por definição, situações apresentadas durativamente e em seu pleno desenvolvimento (cf. item 1.3.9). Que se trata de situações durativas não podemos duvidar, pois em todos os exemplos temos processos; todavia é bom observar que nos exemplos (136) a (138) essa duração não é marcada gramaticalmente $^{3}$ como nos exemplos (139) e (140) (em que a duração é marcada pela repetição do verbo); (141), (142), (144), (146) (em que a duração é marcada pelo adjunto

\footnotetext{
${ }^{2}$ É importante não confundir situações referenciais e situações narradas, pois se isto ocorre, faremos análises falsas ou ficaremos diante de problemas de análise insolúveis.

${ }^{3}$ O próprio Castilho (1967, p.75), na nota 123, alerta contra a confusão que muitas vezes se faz entre categorias lógicas e gramaticais ao comentar que na frase "O dia vem vindo" há apenas a duração marcada pela perífrase e não há os valores incoativo e frequentativo que Eduardo Carlos Pereira anota para esta frase, com base em raciocínios tais como: a) "O dia vem vindo" equivale a "começa um novo dia" donde o valor "incoativo" (= inceptivo); b) como esse ato se processa diariamente temos o valor frequentativo". Nos exemplos (136) a (138) a duração é apenas deduzida do valor do verbo, porque, como veremos, a perífrase TER + PARTICÍPIO marca o acabamento e o completamento como os definimos no item 2.2.2.2 (ver no item 1.3.8 o que diz Câmara Júnior sobre esta perífrase) e o pretérito perfeito (ver item 7.3) marca apenas o completamento da situação apresentando-a em sua totalidade impenetrável à análise, sem excluir a duração, mas fazendo abstração da mesma, que, se necessário, tem de ser expressa por outro meio como um adjunto adverbial, por exemplo.
} 
adverbial); (143) e (145) (em que a duração é marcada por perífrases). Observe-se agora que em nenhum desses exemplos a situação é realmente apresentada "em seu pleno desenvolvimento": no exemplo (137) a perífrase TER + PARTICÍPIO marca a situação como acabada; nos exemplos (141) e (143) a situação é marcada como acabada porque temos verbos estáticos no pretérito perfeito do indicativo (cf. item 7.3); nos exemplos (138) e (142) a situação é apresentada como acabada respectivamente pelo pretérito mais-que-perfeito e pela combinação do verbo no pretérito perfeito do indicativo com um adjunto adverbial (Veja comentários em torno dos exemplos (96), (100) e (101) em 3.1); nos exemplos (139), (140) e (146) a situação é apresentada como acabada, porque o verbo está no pretérito perfeito e se apresenta o término da situação sublinhada: em (139) a decisão de mandar recolher, em (140) o chegar e em (146) a substituição de uma coisa por outra. Somente nos exemplos (136), (144) e (145) não podemos dizer que a situação seja acabada, embora também não possamos dizer o contrário. ${ }^{4}$

Diante das observações do parágrafo anterior pergunta-se: se as situações são apresentadas como acabadas, o aspecto presente nos exemplos (137) a (143) e (146) é o Perfectivo ou Imperfectivo? Se dissermos que é o Imperfectivo teremos o problema de explicar a presença do acabamento que caracteriza o Perfectivo; se dissermos que este último aspecto, teremos de admitir a existência de um Perfectivo durativo e fazer com que o Perfectivo seja caracterizado apenas pelo acabamento, passando a ser um aspecto simples. Se a duração deixar de ser exclusiva do aspecto Imperfectivo, temos de caracterizá-lo de uma outra forma e como ele é o aspecto que se opõe ao Perfectivo podemos dizer que seria caracterizado pela noção de não acabamento. A duração e a pontualidade passariam a caracterizar outros aspectos simples que poderíamos chamar de durativo e pontual, ou viriam a compor aspectos compostos com o Perfectivo e o Imperfectivo resultando 4 aspectos distintos. Como se pode ver, deparam-se nos aqui vários problemas de análise, quando propomos aspectos compostos e também alguns problemas de caracterização dos aspectos pelas noções aspectuais.

Examinemos agora os exemplos (147) a (151) em que Castilho diz haver o aspecto Imperfectivo Terminativo que, conforme ele afirma à página 79, aparece "quando a ação terminou após ter duração". Pela própria definição e pelos exemplos, vemos que a situação é apresentada como acabada e a duração aí não é gramaticalmente marcada, mas apenas pressentida, uma vez que temos processos deduzidos do substantivo sujeito (exemplo 147) ou indicados por este substantivo

\footnotetext{
${ }^{4}$ A situação nos três exemplos é apresentada como completa o que caracterizará a presença do aspecto que chamaremos de perfectivo.
} 
(exemplo 148) ou pelo verbo principal (exemplos 149, 150 e 151). Se a situação é apresentada como acabada não podemos dizer que o aspecto aí presente é o Imperfectivo apenas porque há duração, já que o acabamento ou completamento caracteriza o Perfectivo. Admitindo-se que nestes exemplos haja aspecto Perfectivo e que a duração é expressa ${ }^{5}$ poderíamos dizer que aí temos um Perfectivo Durativo. Isto seria lógico, pois Castilho diz que no exemplo (152) há aspecto Perfectivo Pontual e a única diferença do exemplo (152) em relação ao exemplo (149) é que no primeiro o verbo principal é um evento, portanto pontual, e no segundo é um processo, portanto durativo.

152. "Dr. Borges de Medeiros acaba de reconhecer a vitória do Dr. Júlio Prestes". (Perfectivo Pontual - p.85)

Não existe razão que leve a ignorar que tanto em (149) quanto em (152) existe acabamento e o fato de o verbo principal ser durativo ou pontual não é suficiente para classificar o aspecto em (149) de Imperfectivo e em (152) de Perfectivo. Todos estes fatos são mais evidências de que não se pode caracterizar o Perfectivo como acabado e pontual e o Imperfectivo pela duração. Como se disse anteriormente, parece que o Perfectivo tem que ser um aspecto simples caracterizado apenas pelo completamento (= acabamento) e o Imperfectivo pelo não completamento (= não acabamento).

Nos exemplos (149) a (151) acontece o mesmo que comentamos para os exemplos (133) a (135), mas agora temos terminatividade. A duração apontada aqui é das situações narradas "contar", "passar" e "estudar" e não das situações referenciais "acabar de contar", "acabar de passar" e "terminar de estudar" que são situações pontuais terminativas. Além disso as situações referenciais nas frases (149) a (151) são apresentadas como acabadas. Sendo apresentadas como acabadas e sendo pontuais, as situações das frases em questão não podem ter aspecto Imperfectivo, mas sim Perfectivo. Observe-se ainda que as situações são apresentadas em seu ponto de término e portanto há terminatividade. Para analisar o aspecto destas frases teríamos de acrescentar ao quadro de aspectos compostos um Perfectivo Terminativo, que estaria presente em frases onde tivéssemos eventos cujo completamento (= acabamento) implica o término de uma situação durativa. Com estes exemplos vimos mais alguns problemas de análise e a necessidade de propor mais um aspecto caso se pretenda manter um quadro de aspectos compostos.

\footnotetext{
${ }^{5}$ Dissemos que a duração nos exemplos em questão não é expressa gramaticalmente. Para efeito da classificação aspectual devemos considerar apenas as noções gramaticalmente expressas.
} 
Até agora vimos problemas ligados apenas a quatro noções aspectuais: a duração (considerada em si sem atentar para suas subdivisões - cf. quadro I em 2.2), a pontualidade, o acabamento e o não acabamento. Ao montar seu quadro aspectual, Castilho não levou em conta as noções aspectuais de situação completa e incompleta (cf. item 2.2.2.2). Consideremos a colocação destas noções no quadro aspectual.

Poder-se-ia inicialmente considerar o seguinte raciocínio: a situação completa terá aspecto Perfectivo, pois toda situação completa é acabada e vice-versa; enquanto a situação incompleta terá aspecto Imperfectivo, pois toda situação incompleta é não acabada e vice-versa. Embora pareça lógico e ocorra na maioria das vezes, o que dissemos não se verifica sempre. Vejamos alguns casos que evidenciam o fato de que acabamento e completamento e não acabamento e não completamento ${ }^{6}$ não coincidem necessariamente:

a. em primeiro lugar temos os casos em que a língua apresenta a situação como completa, e faz abstração da oposição acabado/não acabado não marcando a situação nem para uma nem para outra noção. É o que ocorre por exemplo com os verbos atélicos no pretérito perfeito do indicativo ${ }^{7}$ em que a situação é apresentada como completa, como um todo indivisível a exemplo do que ocorre nas frases (100), (136) e (145), mas não é também marcada gramaticalmente como acabada, a exemplo do que ocorre nas frases (97), (137), (141), (143), (149) e (150), em que temos as duas noções;

b. em segundo lugar temos casos em que a situação é apresentada como completa e não acabada (exemplo 153), e casos em que a situação é apresentada como incompleta e acabada (exemplo 154).

\section{João sempre escreveu bem.}

154. João sempre escrevia bem. ${ }^{8}$

Também em frases com verbos de estado e nas frases com verbos atélicos no pretérito imperfeito do indicativo e ênfase entonacional do verbo (Cf. nota 68),

\footnotetext{
${ }^{6}$ Atente-se para o fato de que completamento e acabamento estão sendo tomados agora não como sinônimos, mas no sentido em que foram definidos no item 2.2.2.2.

${ }^{7}$ Câmara Júnior (1970, p.90) ao dizer "no eixo da noção de aspecto opõe [o pretérito] dois conjuntos de formas verbais: um que assinala o processo inconcluso, ou imperfeito, outro, chamado "perfeito", é indiferente a essa assinalização" (grifo nosso) já observa que o pretérito perfeito não marca a situação como conclusa, acabada, entretanto não observou que isto ocorre apenas com os verbos atélicos. (CÂMARA JÚNIOR, J. M. Estrutura da língua portuguesa. Petrópolis: Vozes, 1970. 114 p.).

${ }^{8} \mathrm{Cf}$. argumentação em torno destes casos no item 7.3.
} 
temos exemplos em que a situação é apresentada como incompleta e acabada. É o que vemos em (155) e (156).

\section{João era professor. \\ 156. Pedro nadava muito.}

Diante de tais evidências vemos que não podemos identificar completo e acabado, englobando-os no aspecto Perfectivo e nem incompleto a inacabado, englobando-os no aspecto Imperfectivo. Como o Perfectivo está sendo caracterizado pela noção de acabado e o Imperfectivo pela noção de inacabado ${ }^{9}$, temos de propor pelo menos mais dois aspectos compostos para dar conta da análise do aspecto nos exemplos (153) a (156): o Perfectivo (acabado) Incompleto (exemplos 154, 155 e 156) e o Imperfectivo Completo (exemplo 153). Como há frases em que temos as noções de acabado e completo juntas (exemplos 40, 58, 144) e outras em que temos inacabado e incompleto (exemplos 50 e 55), ter-se-ia de propor, respectivamente, os aspectos Perfectivo Completo e o Imperfectivo Incompleto. Este último, na verdade, teria de ser Imperfectivo Durativo Incompleto já que em (50) e (55) a duração também é marcada.

Como se está vendo, o número de aspectos compostos que temos de propor aumenta cada vez que descobrimos na análise aspectual uma nova combinação de noções aspectuais. Vejamos mais alguns casos.

No exemplo (145) temos marcadas as noções de duração e completamento, mas não a de acabamento. Assim sendo, temos de propor um aspecto Durativo Completo para estes casos que são distintos de frases semelhantes a (143) onde teríamos, em verdade, um Perfectivo (acabado) Durativo Completo. É interessante observar que, para um exemplo como (136), em que a situação não é marcada para as oposições acabado/não acabado e durativo/pontual, mas é apresentada como completa, temos de propor o aspecto simples Completo. Para um exemplo como (157), em que se faz abstração das oposições de acabado/não acabado e completo/ incompleto e só se marca a duração, necessitaremos de um aspecto simples Durativo para classificar o aspecto aí presente.

\section{João ficará atendendo as pessoas.}

\footnotetext{
${ }^{9}$ No quadro aspectual proposto no item 4.2, chamaremos de perfectivo e imperfectivo aspectos caracterizados por outras noções o que, naturalmente, levará a classificações diferentes da que apresentamos neste parágrafo e em outras passagens em que a mesma questão se verifica.
} 
Precisamos de um Imperfectivo Inceptivo para classificar o aspecto de uma frase como a do exemplo (44) e de um Imperfectivo Terminativo para o aspecto de uma frase como a do exemplo (51). Nos exemplos (48) e (158) as únicas noções aspectuais marcadas são, respectivamente, o momento de início e o momento de término das situações e, portanto, os aspectos aí só poderiam ser classificados por aspectos simples que poderíamos chamar de Inceptivo e de Terminativo.

158. Maria terminará de embalar as louças às onze horas.

Até agora, sempre que falamos em duração tratamos de duração contínua limitada. Se tomarmos exemplos em que aparece a duração descontínua limitada teremos novas combinações que levarão a aumentar ainda mais o quadro aspectual. Consideremos os exemplos (159) e (160):

159. Célia anda limpando a casa para mim.

160. Célia andou limpando a casa para mim.

Em (159) a situação é apresentada como não acabada e incompleta ${ }^{10}$, em (160) ela é apresentada como acabada e completa. As duas têm duração descontínua limitada. Podemos chamar de Imperfectivo Iterativo Incompleto o aspecto caracterizado pelas noções aspectuais presentes em (159) e de Perfectivo Iterativo Completo o aspecto caracterizado pelas noções presentes em (160).

Os exemplos examinados até agora deixaram claros alguns pontos: em primeiro lugar observamos que a cada nova noção aspectual que consideramos, novas combinações de noções se tornam possíveis, caracterizando diferentes aspectos compostos; em segundo lugar vemos que, embora as noções aspectuais apareçam combinadas nas frases, também aparecem isoladas; o que nos impede de propor um quadro aspectual apenas de aspectos compostos, levando-nos a propor um quadro aspectual misto; em terceiro lugar notamos que os aspectos compostos nada mais são do que diferentes combinações de aspectos simples tais como Perfectivo, Imperfectivo, Durativo, Pontual, Iterativo, Inceptivo, Terminativo, etc. Tendo em vista: a) que não se pode propor um quadro aspectual apenas de aspectos compostos; b) que os aspectos compostos são na verdade combinações de aspectos simples; c) e que se adotarmos um quadro misto de aspectos simples e aspectos compostos teremos de trabalhar com nada menos de quarenta aspectos, enquanto que um quadro de

\footnotetext{
${ }^{10}$ Não importa que cada realização da situação de limpar seja completa e acabada, para a classificação do aspecto aqui importa é a situação criada pela repetição da situação de limpar.
} 
aspectos simples nos dará apenas treze aspectos; podemos concluir que a proposição de um quadro de aspectos simples é melhor para a análise aspectual por eliminar terminologia cuja existência é desnecessária.

Uma vez alcançado o objetivo a que nos propusemos no início deste item, passemos à proposição do quadro aspectual do Português.

\section{2 - O QUADRO ASPECTUAL DO PORTUGUÊS}

\subsection{1 - PRELIMINARES}

Uma vez que já estabelecemos as noções aspectuais no item 2.2.2 e já verificamos que a melhor alternativa para a análise é a proposição de aspectos simples, isto é, caracterizados por uma única noção, torna-se fácil a criação do quadro de aspectos do Português.

Esclarecemos, desde já, que a terminologia que utilizamos, por vezes se encontra comprometida em outros trabalhos, identificando aspectos cuja caracterização é, frequentemente, bem diversa da do aspecto que aqui identificamos com o mesmo nome. Este é o caso, por exemplo, do aspecto indeterminado que tem caracterização muito diversa da dos aspectos que Castilho (1967) e Guillaume (1969) identificam pelo mesmo nome. Muitos casos semelhantes ocorrem e é preciso estar atento à caracterização que damos de cada aspecto para não criar confusões no momento da análise.

O quadro aspectual do Português está esquematizado no QUADRO III.

A seguir, falaremos de cada aspecto em particular, começando pelo perfectivo e imperfectivo, em virtude de serem os que estão marcados em quase todas as frases, com exceção de uns poucos casos que especificaremos no momento oportuno. Nos exemplos que apresentaremos só será considerado o aspecto em questão no momento, portanto, não faremos referência a outros que, porventura, possam estar presentes. Não nos ocuparemos em comentar caracterizações diferentes de aspectos que receberam o mesmo nome em outros trabalhos.

Neste item falaremos apenas o que se fizer necessário sobre a expressão dos aspectos já que esta questão é tratada especificamente na segunda parte. 
QUADRO III

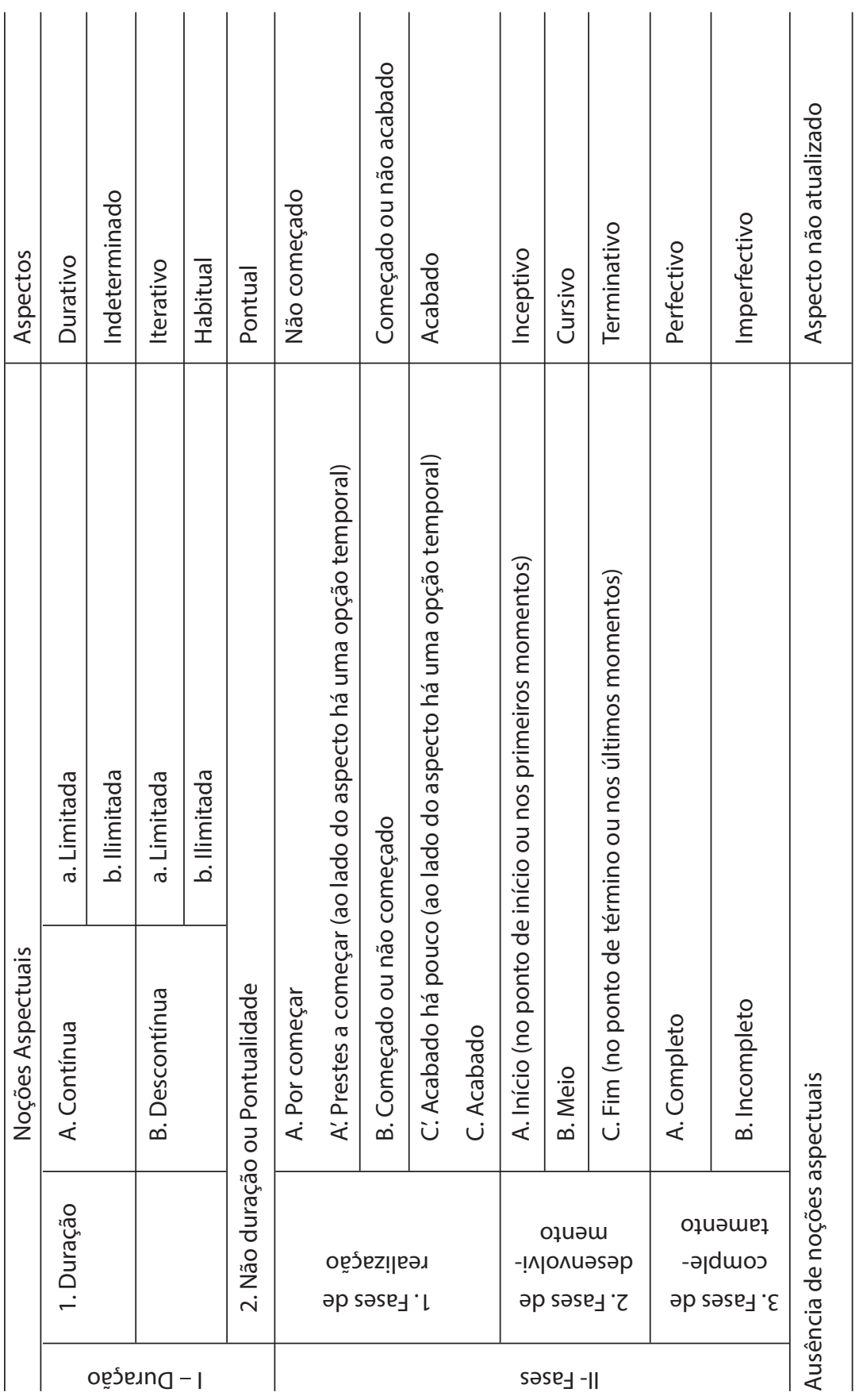




\subsection{2 - PERFECTIVO}

O perfectivo é caracterizado por apresentar a situação como completa ${ }^{11}$, isto é, em sua totalidade. O todo da situação é apresentado como um todo único, inanalisável, com começo, meio e fim englobados juntos. Não há tentativa de dividir a situação em suas fases de desenvolvimento. É como se a situação fosse vista de fora, em sua globalidade.

Exemplos em que temos aspecto perfectivo podem ser encontrados nas frases de números (10), (37), (40) a (42), (46), (52), (56a), (57) a (60), (64), (69), (71), (76) a (86), (91) e (92), (97) a (101), (104) a (110), (112), (113), (122a, b), (123a), (124a), (127), (131), (133) a (147). Abaixo transcrevemos algumas destas frases.

10. Antônio ouviu música o dia todo.

41. Pedro pulara o muro com facilidade.

57. Célia andou indo ao cinema com Élio.

60. Maria ficou olhando as fotos durante várias horas.

82. Eu estive doente, por isso faltei a duas aulas.

Naturalmente estamos nos referindo às situações representadas pelos verbos em negrito em cada exemplo.

\subsection{3 - IMPERFECTIVO}

O imperfectivo é caracterizado por apresentar a situação como incompleta, isto é, não temos o todo da situação e, por isso, normalmente ela é apresentada em uma de suas fases de desenvolvimento. Isto equivale a dizer que, normalmente, a noção que caracteriza o aspecto imperfectivo aparece juntamente com as noções aspectuais representadas pelas fases de desenvolvimento da situação. Aqui, ao contrário do que ocorre no perfectivo, é como se a situação fosse vista de dentro, enfocando-se não o seu todo.

Podemos apontar como exemplo de frases em que temos aspecto imperfectivo as frases de número (8a, b), (9b), (11a-c), (20 a 29), (30a, b), (38), (39), (44), (45), (47), (49 a 51), (53), (54), (65), (67), (68), (70), (72 a 75), (95), (114) a (117), (118a, b), (119a), (120a), (121a), (128), (132), (159) e também os exemplos (161) a (165) abaixo.

${ }^{11}$ Comrie (1976, p.3, 18-19) também caracteriza o perfectivo como apresentando a situação em seu todo, completa, mas acrescenta a esta outras noções aspectuais. 
161. Estou escrevendo há dias e começo a sentir-me fatigado.

162. A competição iniciava-se naquele instante.

163. A festa terminava quando ele saiu.

164. Seus atos vêm escandalizando a todos.

165. A mistura ia endurecendo lentamente.

Antes de continuarmos a falar dos aspectos, queremos anotar que o aspecto perfectivo seleciona, para as frases em que aparece, adjuntos adverbiais de tempo que indicam momentos e períodos de tempo determinados e/ou completos (exemplos 166a, 167a, 168a, 169a), enquanto o imperfectivo aceita adjuntos adverbiais de tempo que indicam momentos e períodos de tempo indeterminados e/ou incompletos (exemplos 166b, 167b e 168b). Quando numa frase temos aspecto imperfectivo e adjunto adverbial de tempo que indica um período de tempo completo, a frase só será aceita num sentido iterativo e o período de tempo será indeterminado (exemplos 167b e 168b). Frases com aspecto imperfectivo só aceitam adjunto adverbial de tempo determinado se este indicar um momento no qual a situação já estava, está ou estará em desenvolvimento (exemplo 169b - ver nota 72), caso contrário o momento será indeterminado e a frase terá sentido iterativo (exemplos 170a, b).

166. a - Ricardo estudou há três dias. (É pontual e determinado) b - Ricardo estudava há três dias. (Havia já três dias que estava estudando - é incompleto).

167. a-Ricardo caminhou meia hora. (O período de tempo é completo e determinado: uma meia hora determinada).

b - Ricardo caminhava meia hora. (A frase só é válida no sentido iterativo em que cada realização da situação tem duração de meia hora - "meia hora" é indeterminado).

168. a-As samambaias brotaram em junho. (Um junho determinado). b - As samambaias brotavam em junho. (Junho é indeterminado e a frase só vale no sentido iterativo). ${ }^{12}$

169. $\mathrm{a}-\mathrm{O}$ bebê nasceu às cinco horas. ("às cinco horas" é determinado) $\mathrm{b}$ - $\mathrm{O}$ bebê nascia às cinco horas. ( $\mathrm{A}$ interpretação iterativa não sendo possível "as cinco horas" será tomado como determinado e a frase só será possível se interpretada como "O bebê estava nascendo às cinco horas").

170. a - Papai acordava às cinco horas. ("às cinco horas” é indeterminado e a frase tem interpretação iterativa).

${ }^{12}$ No exemplo (168b) se "em junho" for tomado como um momento determinado e não como um período a frase poderá ser aceita com o sentido de "As samambaias estavam brotando em junho". 
b - Mamãe dormia até às sete horas. (Só é possível na interpretação iterativa e "até às sete horas" é indeterminado, indicando o momento de término de cada realização da situação). ${ }^{13}$

\subsection{4 - Durativo}

O durativo é caracterizado por apresentar a situação como tendo duração contínua limitada.

São exemplos em que temos aspecto durativo as frases de números $(8 \mathrm{a}, \mathrm{b})$, (9a, b), (10), (11a, b), (38), (39), (42), (49), (55), (56b), (58), (60), (65), (67 a 75), (82), (120a), (122a), (126), (128), (131), (132), (139), (140), (143 a 146), (157). Abaixo transcrevemos cinco destas frases.

8a. $\quad$ Ele estava nadando desde as 6 horas da manhã.

42. O treinador do time esteve doente.

68. Nossa amizade estreitava-se.

69. O amor dos tios foi transformando aquela criança.

157. João ficará atendendo as pessoas.

Importa esclarecer que não se pode falar em aspecto durativo pelo simples fato de termos na frase um processo ou um estado que são situações durativas. É preciso ver se na frase em questão a situação está, por qualquer meio, marcada como durativa, pois, como já vimos, até mesmo situações pontuais podem ser apresentadas como durativas (cf. comentários em torno dos exemplos 114 a 117). Além disso, a forma verbal utilizada pode fazer abstração da oposição durativo/ pontual, não marcando a situação nem como uma nem como outra coisa, independente do fato de ser ou não um processo. É o que acontece, por exemplo, nas frases (40), (41), (43), (48), (59), (64), (76 a 79), (80), (83 a 86), (91), (92), (96), (97 a 101), (104), (106 a 110), (112), (113), (136 a 138), (147 a 151), na quase totalidade das quais temos processos, mas nenhuma marcação relativa à oposição aspectual durativo/pontual.

\footnotetext{
${ }^{13}$ Falaremos sobre a influência do aspecto na estruturação e interpretação de frases sempre nos pontos em que estivermos falando do elemento que afeta tal interpretação e estruturação.
} 


\subsection{5 - INDETERMINADO}

O indeterminado apresenta a situação como tendo duração contínua ilimitada. Temos este aspecto nos exemplos de número (12) a (19).

Como se pode ver pelos exemplos, ilimitado aqui não significa infinito, mas antes sem limites conhecidos ou perceptíveis, ainda que intuitivamente. Como já dissemos no item 2.2, as situações expressas em frases com aspecto indeterminado são atemporais ou antes onitemporais, já que são tomadas como elementos "universalizados", válidos para todo o tempo, que o falante torna válidos para o momento presente através de sua enunciação, mesmo que a situação não esteja ocorrendo no momento da fala. Assim se alguém diz, por exemplo, a um companheiro quando está viajando:

(171) Eu trabalho em uma loja de peças.

É evidente que a frase não tem a significação de "estou trabalhando agora na loja". O tempo sugerido é tanto o passado quanto o futuro e hipoteticamente o presente, isto é, a frase é onitemporal.

Como já ressaltamos no item 2.2, em consequência da pouca significação que apresenta para o espírito humano uma duração ilimitada, há uma tendência para ignorá-la total ou parcialmente. Isto apaga ou enfraquece a expressão do aspecto indeterminado, levando o verbo a referir-se só ou mais à situação em si já que o tempo também foi anulado. Isto quer dizer que a separação entre o indeterminado e o não aspecto é mínima e por vezes é difícil saber se temos um ou o outro.

Para nós o aspecto indeterminado não é, como para Castilho (1967), uma ausência de aspecto, embora admitamos que neste caso há um enfraquecimento da noção aspectual.

As frases que apresentam aspecto indeterminado têm basicamente as seguintes funções: ${ }^{14}$

a. apresentar verdades eternas ou tidas como tais. Estas verdades podem ser científicas (exemplos 12, 172 a 174), ou da experiência de vida que aparecem então sob a forma de máximas, provérbios ou simples afirmações de caráter geral (exemplos 13, 15, 175 a 177) ou teológicas, metafísicas, religiosas (exemplos 16 e 17), etc.

\footnotetext{
${ }^{14}$ Castilho (1967, p.102-106) e IMBS (1960, p.24-30) também comentam as funções das frases que apresentam este aspecto.
} 
172. Os ângulos internos do triângulo somam 180 graus.

173. O ano tem 365 dias.

174. Os corpos se atraem na razão direta das massas e na razão inversa do quadrado da distância.

175. Macaco velho não põe a mão em cumbuca.

176. Nunca somos suficientemente prudentes.

177. Só um louco ri da desgraça alheia.

b. Caracterizar seres ou coisas. ${ }^{15}$ Exemplos (14), (18), (19), (178 a 182)

178. Esta obra apresenta o homem feliz.

179. João é um rapaz inteligente.

180. A zebra é herbívora.

181. A onça ataca, quando está faminta.

182. Maria fala cinco línguas.

Em exemplos como (14), (181) e (182) a característica é apresentada como uma disposição, uma habilidade ou capacidade para realizar a ação. No exemplo (181) temos uma caracterização no limite do habitual que comentaremos ao falar deste aspecto.

c) Definir seres e coisas. Exemplos:

183. Lâmpada - objeto que serve para iluminar.

184. Música - Arte através da qual se combinam os sons de modo agradável ao ouvido.

185. Musicado - que se desenrola ao som da música.

\subsection{6 - ITERATIVO}

O iterativo se caracteriza por apresentar a situação como tendo duração descontínua limitada. Veja-se no item 2.2.2.1 o que falamos sobre duração descontínua.

São exemplos de frases em que temos o aspecto iterativo as frases de números (11c), (21 a 24), (30-b), (57), (118a, b), (119a), (121a), (159), (160) e também os exemplos (186) a (188) abaixo.

\footnotetext{
${ }^{15}$ É em virtude dessa função que Joos (1968, p.110-111) chama o aspecto presente nestas frases de "characterizing generic aspect" (aspecto genérico caracterizador). (JOOS, M. The english verb: form and meanings. London: University of Wisconsin Press, 1968. 251 p.).
} 
186. "Nosso filólogo andou falhando no começo do ano". (Ciro dos Anjos)

187. Ela me acenou várias vezes.

188. As crianças ora choravam, ora brincavam. ${ }^{16}$

O modo de repetição normalmente é marcado por meios lexicais: a repetição alternada é marcada por conjunções coordenativas alternativas (exemplo 188); a frequência de repetição é marcada por adjuntos adverbiais tais como "muitas vezes", "algumas vezes", "seguidamente", "raramente", "sempre", etc. que de uma certa forma também quantificam a repetição; a regularidade da repetição também é marcada por adjuntos adverbiais tais como "todos os dias" (exemplo 20), "de tempos em tempos" (exemplo 23), "aos domingos" (exemplos 30a, b), "duas vezes por semana", "sempre à mesma hora", "cada manhã", etc.; a negação de repetição regular é marcada por expressões adverbiais ao mesmo tempo negativas e temporais como "nunca" (exemplo 28), "não [...] jamais" (exemplo 189), "nem sempre" (exemplo 190), jamais, etc.

189. Mariana não escuta jamais os conselhos que lhe dão.

190. Nem sempre o diretor começa a atender às oito horas.

Como já ressaltamos no item 2.2 os adjuntos adverbiais marcadores de iteração e de sentido totalizador tais como "todos os dias", "sempre", "nunca", "invariavelmente" etc. são mais utilizados nas frases de sentido iterativo habitual.

A exemplo do que acontece com o aspecto durativo, para dizermos que em dada frase temos aspecto iterativo, é preciso que a repetição criada pela duração descontínua limitada esteja marcada gramaticalmente. Assim, por exemplo, nas frases em que temos verbos que indicam situações intrinsecamente iterativas tais como "saltitar" (dar pequenos e repetidos saltos), "cuspinhar" (cuspir a miúdo e pouco de cada vez), "repicar" (tanger repetidas vezes); não teremos aspecto iterativo simplesmente pela presença de tais verbos na frase (cf. também item 9.3.2), como também não temos aspecto durativo simplesmente por ter um processo na frase. Assim, nas frases (191) a (193) não temos aspecto iterativo, porque este não está marcado por nenhum elemento da frase, enquanto nas frases (194) a (196) há aspecto iterativo marcado pelas perífrases. ${ }^{17}$

\footnotetext{
${ }^{16}$ Exemplo (186) apud Castilho (1967, p.98). Exemplo (188) é de Castilho (1967, p.60).

${ }^{17}$ Cf. capítulo 8 .
} 
191. A menina saltitava de alegria quando entrei na sala.

192. Maria veio da cozinha cuspinhando para expulsar da boca o gosto amargo do remédio que tomara.

193. O sacristão está repicando o sino para chamar o povo à festa.

194. Minha filha tem saltitado como um cabritinho feliz.

195. Aquele velho anda cuspinhando em toda a casa.

196. O padre tem repicado o sino todas as tardes para lembrar ao povo seus deveres religiosos.

\subsection{7 - HABITUAL}

O habitual ${ }^{18}$ é o aspecto que apresenta a situação como tendo duração descontínua ilimitada. (cf. item 2.2.2.1 o que falamos sobre duração descontínua).

Temos aspecto habitual nos exemplos de números (20), (25 a 29), (30a), (153) e (197 a 203) abaixo.

197. Sempre que chegavam visitas, mamãe fazia biscoitos fritos.

198. Ele usava fumar após as refeições.

199. Todas as manhãs ela me cumprimenta com um sorriso.

200. Se fica sem dormir ela adoece.

201. Embora papai costumasse chegar às seis horas em casa, nunca jantamos antes das oito.

202. Embora Valdete viva caminhando pelo bosque, não conhece todos os seus recantos.

203. Quando fica nervoso, Rafael desata a engolir tudo o que é comestível que encontra pela frente.

Considerando o fato de que a habitualidade não é uma noção aspectual, poderse-ia propor a reunião dos aspectos iterativo e habitual num só aspecto já que ambos se caracterizam basicamente pela repetição originada da duração descontínua. Isto, entretanto, implicaria desconsiderar a distinção entre duração limitada e ilimitada, que é real, representando duas noções aspectuais distintas.

Como já dissemos no item 2.2.2.1, as frases em que temos aspecto habitual, em virtude de duração ilimitada deste, podem ser usadas com a função de caracterizar

${ }^{18}$ Já dissemos no item 2.3 que a habitualidade não é uma noção aspectual, mas sim a duração descontínua ilimitada de que ela resulta. 
seres ou coisas, exatamente do mesmo modo que as frases em que temos aspecto indeterminado. Como nestas, aqui também temos a mesma onitemporalidade, principalmente com o verbo no presente do indicativo. Vejam-se os exemplos (31 a 33) e (204 a 207).

204. Paulo fuma muito.

205. As crianças gostam de animais.

206. Hélio deixa de ir trabalhar por qualquer problema que surja.

207. Ivo sempre começa o trabalho com má vontade, mas depois se entusiasma.

Como a única distinção entre o aspecto indeterminado e o habitual é a duração ser contínua ou descontínua, em algumas frases com mesma função torna-se difícil, na análise, perceber se temos um ou outro aspecto. É o que acontece, por exemplo, nas frases (208) e (209). Na verdade estes casos parecem ser limítrofes entre um e outro aspecto.

208. Se a quantidade de luz aumenta, os brotos começam a morrer. (Aqui parece haver uma maior tendência para o aspecto indeterminado).

209. Quando a quantidade de luz aumenta, os brotos começam a morrer. (Aqui parece haver uma maior tendência para o aspecto habitual).

Quando temos o aspecto habitual, naturalmente temos várias realizações da mesma situação. É comum que a língua atribua a cada realização da situação um determinado aspecto. Pode-se observar isto nos exemplos (210) a (214) abaixo, onde, entre parênteses, especificamos o aspecto ou os aspectos com que cada realização da situação habitual é apresentada.

210.) Todo dia, quando chego, Verinha está batendo a máquina. Imperfectivo, cursivo, não acabado, durativo) - o fato de Verinha estar batendo a máquina quando chego é habitual e portanto se repete, tendo aspecto imperfectivo, habitual e não acabado.

211. Ele começa a treinar sempre às 6 da manhã. (Imperfectivo, inceptivo).

212. Às 6 horas, o chefe de seção de pessoal sempre está conferindo o ponto. (Imperfectivo, cursivo, durativo, não acabado). 
213. João normalmente ia rabiscando um papel enquanto conversava. (Imperfectivo, durativo).

214. Sempre que chego em casa meu filho está terminando de fazer os deveres. (Imperfectivo, terminativo, não acabado).

Nestes casos, ao fazer a análise aspectual, é preciso não confundir o aspecto da situação única criada pela repetição com o aspecto atribuído a cada realização da situação. Importa notar que, nestes casos, normalmente a habitualidade é marcada ou condicionada por um elemento adverbial, seja um adjunto, seja uma oração. No aspecto iterativo o mesmo fato se dá, embora pareça ser menos frequente.

\subsection{8 - PONTUAL}

O aspecto pontual é caracterizado por apresentar a situação como pontual, ou seja, como não tendo duração. Logicamente toda situação tem duração, mas, linguisticamente, a duração só é considerada quando é expressiva (cf. nota 30). Já dissemos no item 3.1 que o Português tende a apresentar as situações mais como durativas do que como pontuais, daí encontrarmos um número bem maior de frases com aspecto durativo do que com aspecto pontual e também um menor número de elementos marcadores de aspecto pontual.

Os dois casos de expressão do aspecto pontual que parecem ser mais frequentes no Português ocorrem com o presente do indicativo nos seus usos denominados de "presente momentâneo" (exemplos 215 a 217) e "presente histórico ou narrativo" (exemplos 218 a 220). O pontual com o presente momentâneo só ocorre com verbos de evento, pois com verbos de processo ou estado teremos habitual ou cursivo; ${ }^{19}$ e também em descrições simultâneas, isto é, quando falamos da situação no exato momento em que ela ocorre. Se não tivermos uma descrição simultânea, as frases de presente do indicativo e aspecto pontual serão automaticamente interpretadas como de presente histórico que, na verdade, cria o efeito estilístico de alguém que narra o fato no instante em que ele ocorre, como numa descrição simultânea, ou então será visto como habitual.

215. Raulzinho pega a bola e atira para Roberto. (Dito pelo locutor que irradia um jogo).

216. Os carros partem neste instante com Fittipaldi à frente. ( $\mathrm{Na}$ irradiação de uma corrida).

\footnotetext{
${ }^{19}$ Como veremos no capítulo 5 , o aspecto pontual é incompatível com o habitual e o cursivo.
} 
217. Pedro chega na sala e descobre angustiado que sua mãe está morta. (Dito, por exemplo, por alguém que vê um filme e comenta as cenas, digamos, numa aula).

218. O Visconde de Mauá funda estaleiros e inicia no Brasil a construção naval.

219. Caxias ataca o inimigo e vence-o.

220. Desconsiderado em sua terra, Marcos vai para o Rio, estuda e, anos mais tarde, quando volta, se surpreende com o tratamento que lhe dispensavam.

Embora nem sempre isto ocorra, o uso do pretérito perfeito do indicativo pode resultar em frases com aspecto pontual. Veja os exemplos (221) e (222):

221. Um dia Mariana descobriu o que podia fazer com o dinheiro.

222. Achei seu anel dentro da gaveta do criado.

Somente o pretérito perfeito do indicativo de verbos que indicam situações estritamente pontuais é que marca o aspecto pontual. ${ }^{20}$

A presença ou não do aspecto pontual pode ser detectada pela possibilidade ou não de colocação na frase de um adjunto adverbial durativo. Se pudermos colocar na frase um adjunto adverbial de tempo indicador de duração é porque aí não temos aspecto pontual marcado. Não se pode inferir também que se tenha aspecto durativo, pois se a mesma frase aceitar um adjunto adverbial de tempo pontual é porque a situação da frase não é marcada para a oposição pontual/durativo, havendo abstração da duração. Verkuyl (1972) já aponta esta restrição de seleção entre o aspecto e o adjunto adverbial, mostrando para o alemão que uma frase com aspecto durativo só aceita adjunto adverbial de duração e que a frase com aspecto pontual só aceita adjunto adverbial pontual. Só isso pode explicar a agramaticalidade de uma frase como (223).

223. * Achei seu anel dentro da gaveta do criado durante cinco minutos.

Deve-se ter em mente que o adjunto adverbial usado para detectar a presença do aspecto pontual ou durativo deve indicar o tempo de realização da situação, o seu tempo de ocorrência, ou o teste não será válido, pois, quando o adjunto adverbial

\footnotetext{
${ }^{20}$ Sobre a indicação do aspecto pontual pelo pretérito perfeito do indicativo veja também o que dizemos no item 7.3.
} 
pontual indica um dos momentos em que a situação está, estava ou estará se dando, podemos ter um adjunto adverbial pontual com aspecto durativo como em (224).

224. Às duas horas Maria ainda estava estudando.

É comum no estudo do aspecto dizer-se que o perfectivo apresenta a situação como pontual. Se assim fosse, em todas as frases em que tivéssemos perfectivo não poderíamos ter adjuntos adverbiais de duração, mas não é isso o que ocorre, como se pode ver pelos exemplos $(225 \mathrm{a}, \mathrm{b})$ e $(226 \mathrm{a}, \mathrm{b})$ em que temos, com a mesma forma perfectiva, adjuntos adverbiais tanto durativos quanto pontuais.

225. a - João correu às quinze horas.

b - José correu durante trinta minutos.

226. a - Maria conversou comigo às nove horas.

b - Maria conversou comigo por muito tempo.

Além disto, o aspecto perfectivo, muito frequentemente, aparece combinado ao durativo, como se pode ver nas frases (10), (42), (58), (60), (69), (71), (82), (122a), (139), (140), (143), (144) e (146). Isto deixa claro que a forma perfectiva não é, necessariamente, também pontual.

Considerando que o aspecto pontual apresenta a situação como não tendo duração e, portanto com o início, meio e fim coincidentes, vemos que é impossível apresentar uma situação com aspecto pontual, como incompleta. Isto significa que toda situação com aspecto pontual terá de ser apresentada como completa, isto é, com aspecto perfectivo. Fica assim esclarecida a relação entre o perfectivo e o pontual: não é todo perfectivo que é pontual, como normalmente se diz; mas todo pontual é que é perfectivo.

A diferença entre frases como (215 a 220) e (221), (222) é que nestas temos aspectos pontual, perfectivo e acabado marcados, enquanto nas primeiras temos marcados apenas os aspectos perfectivo e pontual, havendo pois abstração da distinção acabado/não acabado.

\section{2 .9 - NÃO COMEÇADO}

O aspecto não começado se caracteriza por apresentar a situação na fase anterior ao início de sua realização, portanto como algo por começar. Depreende-se da frase em que ocorre tal aspecto que há ou houve "intenção" ou "certeza" de a situação se realizar. As frases de números (7c), (34 a 37) e (132) são exemplos em que temos este aspecto. Abaixo transcrevemos três destes exemplos: 
35. Pedro está para emoldurar o quadro.

37. Este livro ficou por ler, pois não tive tempo.

132. A cozinha está por limpar.

Como se pode observar, esse aspecto é normalmente marcado por perífrases: ESTAR + PARA (ou POR) + INFINITIVO e FICAR + POR + INFINITIVO, etc.

Alguém poderia argumentar que o que temos aqui é uma marcação de futuro e não de uma fase da situação, que caracteriza um aspecto. Isto não é verdade pois, se assim fosse, teríamos de admitir que toda situação apresentada por uma forma de sentido futuro seria não começada e isto não ocorre. Em primeiro lugar, em frases como (227) a (229), não podemos garantir se a situação é começada ou não começada, isto é, não há marcação relativa a esta oposição. Nestes exemplos só podemos saber se a situação é começada ou não pelo conhecimento do mundo real.

227. O conferencista falará até às $22 \mathrm{~h}$ e $30 \mathrm{~min}$. (Ele pode já estar falando ou não).

228. O médico acabará a operação antes de você chegar. (Ele pode já estar operando ou não).

229. Maria terminará de limpar a casa antes do almoço. (Ela pode já estar limpando ou não).

Em segundo lugar, podemos ter frases no futuro que têm marcado o aspecto começado, como é o caso dos exemplos (230) a (232).

230. Estará chovendo quando chegarmos ao Rio.

231. Quando vocês começarem a distribuir os folhetos continuarei falando.

232. Prosseguiremos lutando mesmo que alguns de nós sejam mortos.

Estes três casos são suficientes para demonstrar que tempo futuro e aspecto não começado são distintos e não devem ser confundidos, mesmo quando um só recurso é usado para assinalar os dois, como é o caso da perífrase ESTAR + PARA + INFINITIVO que marca aspecto não começado e futuro próximo (iminência de ação). Assim, não se deve confundir a ideia que se tem de futuro como algo não começado (o que nem sempre é verdade, como vimos), com a noção gramatical aspectual de não começado.

É preciso observar que com a perífrase ESTAR + POR + INFINITIVO o aspecto não começado é da situação narrada, pois a situação referencial que é um 
estado (ver comentários em torno do exemplo 132) terá um outro aspecto. Em (132), por exemplo, a situação referencial "está por limpar" tem aspectos imperfectivo, durativo, cursivo e não acabado, e a situação narrada "limpar" tem aspecto não começado. Ao fazermos a análise aspectual, é preciso estarmos atentos para este tipo de problema, pois sem a distinção entre as duas situações (narrada e referencial) estaríamos diante de um impasse, já que os aspectos cursivo e não começado são incompatíveis como veremos no capítulo 5 .

Não encontramos referência ao aspecto não começado em nenhum outro trabalho que trata do aspecto, especificamente ou não.

\subsubsection{0 - NÃO ACABADO OU COMEÇADO}

O aspecto começado ou não acabado se caracteriza por apresentar a situação já em realização, ou seja, após o seu momento de início e antes de seu momento de término. Portanto, se a situação é apresentada em seus primeiros ou últimos momentos, também temos o aspecto começado ou não acabado. São exemplos em que temos este aspecto, entre outras, as frases de números (8a, b) (11a-c), (20 a 25), (38), (39), (44), (47), (49 a 51), (53), (65), (67), (68), (70), (95), (114 a 121), (125), (126), (128), (130), (131), (159), (161 a 165), (166b), (191 a 196), (199), (202), (214), (230 a 232). Abaixo transcrevemos alguns destes exemplos.

11c. Minha cabeça tem doído muito.

38. Os rapazes continuam jogando apesar da chuva.

50. Estou lendo um livro interessante.

53. Raquel terminava de escrever a carta quando o telefone tocou.

126. José está doente.

164. Seus atos vêm escandalizando a todos.

A proposição de dois nomes para o mesmo aspecto se explica pelo fato de ele se opor a dois outros numa posição intermediária. Veja a este respeito o que dissemos no item 2.2.2.2 ao falarmos da fase que caracteriza este aspecto.

\subsubsection{1 - ACABADO}

O aspecto acabado se caracteriza por apresentar a situação após seu momento de término, portanto como concluída, acabada, terminada. Ele aparece, por exemplo, nas frases de números (7a), (40 a 43), (46), (52), (56a), (58), (59), (64), (71), (72 a 
75) $)^{21},(76$ a 79), (80 a 83), (91), (97), (99), (101), (104 a 110), (112), (113), (122a, b), (127), (133 a 135), (137 a 143), (146 a 152), (154). Abaixo transcrevemos os exemplos (40), (59), (71) e (149).

40. Maria leu o livro.

59. Quando eles voltarem, já terei preparado o lanche.

71. O pobre animal morreu pouco a pouco.

149. "Só de ouvir dizer, porque, como acabo de contar, nunca os vira juntos".

Muitas vezes a noção de situação acabada aparece sob a forma de cessamento (cf. item 2.3). Isto pode ser observado nos exemplos (42), (58), (80 a 84), (122a, b), (127), (141) e (143), alguns dos quais transcrevemos abaixo.

42. O treinador do time esteve doente.

58. A menina esteve balançando lá fora por muito tempo.

81. Eu, um dia, fui o maior malabarista do mundo.

122b. Eu já soube matemática muito bem.

4.2.12 - INCEPTIVO

O aspecto inceptivo se caracteriza por apresentar a situação em seu ponto de início ou em seus primeiros momentos. No segundo caso ele é mais facilmente perceptível. Podemos observá-lo nas frases de números (44 a 48), (106), (133 a 135), (161 - a $2^{\text {a }}$ locução), (162), algumas das quais transcrevemos abaixo.

44. Os marceneiros estão começando a armar o telhado.

47. Daniel principiava a arrumar a mala quando cheguei em sua casa hoje de manhã.

48. Jorge começará a soltar os fogos de artifício às 20 horas.

106. José começou a falar na segunda aula.

161. Estou escrevendo há dias e começo a sentir-me fatigado.

\footnotetext{
${ }^{21}$ Em frases como estas o aspecto acabado é da situação narrada e não da referencial. Veja o que dizemos a este respeito no item 5.2.
} 


\subsubsection{3 - CuRSIVO}

$\mathrm{O}$ aspecto cursivo se caracteriza por apresentar a situação em pleno desenvolvimento, ou seja, concebida como já tendo passado seus primeiros momentos e ainda não tendo atingido seus últimos momentos. Em outras palavras, a situação é apresentada na fase do meio de seu desenvolvimento.

São exemplos em que temos este aspecto, entre outras, as frases de números (8a, b), (11a, b), (34), (38), (39), (49), (50), (55), (65), (67), (68), (70), (72 a 75), (95), (114 a 117), (120a), (126), (128), (130), (132), (164), (165), (191 a 193) e (230 a 232). Abaixo transcrevemos algumas.

11) a - José lia um romance quando sua irmã chegou.

b - Estamos fazendo um bolo para mamãe.

38. Os rapazes continuam jogando apesar da chuva.

55. O presidente estava falando desde as cinco horas.

65. A valente tropa fraquejava.

164. Seus atos vêm escandalizando a todos.

165. A mistura ia endurecendo lentamente.

192. Maria veio da cozinha cuspinhando para expulsar da boca o gosto amargo do remédio que tomara.

Pode parecer estranho falar que um estado se encontra em pleno desenvolvimento, e neste sentido, dizer que uma frase indicando estado tem aspecto cursivo, todavia a estranheza desaparece se lembrarmos que com isto estamos dizendo apenas que o estado existe e não está nem em seu início, nem em seu término. Temos aspecto cursivo quando a situação é um estado nas frases de números (72 a 75), (126), (128), (130), (132) e (233) abaixo, em que transcrevemos também dois dos exemplos citados.

72. Tenho a lição estudada.

75. Quando chegamos à fazenda o cafezal estava destruído.

233. Daniel está feliz com o novo emprego.

O que dissemos para os estados vale para qualquer situação expressa por um "verbo estático". Vejamos os exemplos (234) e (235) em que há aspecto cursivo.

234. Irene sabe matemática muito bem.

235. Oscar possui muitos bens. 
Também quando temos aspecto iterativo, devido à duração descontínua, pode parecer estranho falar em aspecto cursivo. Entretanto é preciso lembrar que estamos falando em cursividade da situação criada pela repetição e não de cada realização da situação que se repete. Temos aspecto cursivo ao lado do iterativo nas frases de números (11c), (21), (22), (24), (30b), (118a, b), (119a), (121a), (159), (188); duas das quais transcrevemos abaixo.

11c. Minha cabeça tem doído muito.

159. Célia anda limpando a casa para mim.

Normalmente não falaremos em cursivo quando tivermos iterativo ou habitual.

\subsubsection{4 - TERMinATIVO}

O aspecto terminativo se caracteriza por apresentar a situação nos seus últimos momentos ou em seu momento de término. Ele é percebido mais facilmente no primeiro caso. Podemos observá-lo nas frases de números (51 a 54), (109), (163), três das quais transcrevemos abaixo.

51. Espere um momento que estou acabando de arrematar seu vestido.

53. Raquel terminava de escrever a carta quando o telefone tocou.

109. Rita terminou de limpar a casa às 11 horas.

Não há aspecto terminativo em frases como (149), (150), (152) com a perífrase ACABAR + DE + INFINITIVO, pois aí a situação não é apresentada em seu ponto de término, mas alguns instantes após o mesmo. Transcrevemos a frase (152) abaixo.

152. "O Dr. Borges de Medeiros acaba de reconhecer a vitória do Dr. Júlio Prestes".

Cabe aqui uma observação sobre os aspectos inceptivo e terminativo e as situações pontuais inceptivas e terminativas. Muitas vezes o início ou término de uma situação durativa (processo ou estado) é expresso lexicalmente por outro verbo, tais como os listados em (236) (cf. o que dissemos a este respeito no item 3.2). 
236. a - Verbos que indicaram início de um processo:

partir (início de ir ou vir)

nascer (início de viver)

b- Verbos que indicam início de um estado, normalmente chamados de incoativos: 22

adoecer (início de estar doente)

engordar (início de estar gordo)

endurecer (início de estar duro) ${ }^{23}$

c - Verbos que indicam término de um processo:

chegar (término de ir ou vir)

morrer (término de viver)

vencer (término de disputar, lutar)

achar (término de procurar)

decidir (término de pensar o que fazer)

Quando temos frases com estes verbos, tais como os exemplos (104) e (116) - com verbos do tipo dos de (236a); (64 a 68) e (105) - com verbos do tipo dos de (236b) e (71), (99), (107), (108), (110), (115) - com verbos do tipo dos de (236c), não podemos dizer que aí temos aspectos inceptivo ou terminativo pela simples presença destes verbos. Isto porque a incepção ou a terminação dos processos e estados não estão marcadas gramaticalmente, uma vez que estes não estão sendo apresentados no seu início ou término, pois o que fazemos é falar de uma situação cuja realização implica o início ou término deles e não deles em si. Embora logicamente saibamos que tais verbos expressam situações que representam o início ou o término de outras, não podemos dizer que os aspectos em questão foram atualizados, assim como não podemos falar em aspecto durativo ou pontual por termos processos ou eventos na frase e não podemos falar em aspecto iterativo, porque a frase tem um verbo do tipo de saltitar (cf. 4.2.6 - aspecto iterativo).

\subsubsection{5 - NÃO ASPECTO}

Como vimos no item 2.2.2, pode acontecer que nenhuma noção aspectual esteja presente na frase. Neste caso, não haverá referência à duração ou às fases da situação, pois a categoria de aspecto não terá sido atualizada. Na segunda parte,

\footnotetext{
${ }^{22}$ Muitos autores vinculam os verbos incoativos ao aspecto inceptivo, pois, se eles indicam mudança de estado, implicam no início de um novo estado (cf. item 2.3.3).

${ }^{23} \mathrm{Nem}$ todos os verbos incoativos são eventos. Na verdade, a maioria deles parece ser processo. De qualquer forma são situações inceptivas
} 
veremos alguns casos em que normalmente isto ocorre. As frases (61) a (63) e as frases (237) a (241) abaixo são exemplos nos quais o aspecto não foi atualizado.

237. Você tem de prestar atenção.

238. Hei de passar no concurso.

239. As crianças precisam se alimentar bem.

240. Posso servir o jantar?

241. Se ele pagar a taxa até amanhã, não haverá problema.

\section{3 - A ATUAlização DO ASPECTO}

Pelo quadro III vemos que existem quatro grupos de distinções aspectuais: um ligado à duração e três ligados às fases. Além da ausência total de atualização do aspecto, podemos ter a não atualização de um ou outro grupo de distinções em dada frase. Isto significa que uma forma verbal não precisa estar marcada para os quatro tipos de distinções aspectuais, mas pode estar marcada apenas para uma, duas, ou três destas distinções. Assim, por exemplo, uma forma verbal pode estar marcada apenas para a distinção perfectivo/imperfectivo sem estar marcada para as outras três distinções e assim por diante. Portanto, ao proceder à análise aspectual de uma frase, não se tem, obrigatoriamente, que dizer aspectos referentes às quatro distinções aspectuais, mas apenas aspectos referentes às distinções para as quais a situação expressa está marcada. Abaixo damos alguns exemplos de análise em que se pode observar o que acabamos de dizer.

242. João foi esquecendo aquela cena horrível. (perfectivo, durativo).

243. As roseiras que podei começam a brotar. (imperfectivo, inceptivo, começado).

244. Joana está pintando um quadro para mim. (imperfectivo, durativo, não acabado, cursivo).

245. Rafael começará a trabalhar amanhã. (inceptivo).

246. Acabamos de receber um telegrama de João. (acabado, pontual).

247. Eu corro $3 \mathrm{~km}$ todos os dias de manhã. (imperfectivo, habitual, não acabado).

248. César já pintou muito hoje. (perfectivo). 
O aspecto verbal no Português: a categoria e sua expressão 